\title{
Discovery and synthesis of novel benzofurazan derivatives as inhibitors of influenza $A$ virus
}

\author{
Ulrich Kessler $^{\mathrm{a}}$, Daniele Castagnolo ${ }^{\mathrm{b}}$, Mafalda Pagano ${ }^{\mathrm{b}}$, Davide Deodato ${ }^{\mathrm{b}}$, Martina Bernardini ${ }^{\mathrm{b}}$, \\ Beatrice Pilger ${ }^{\mathrm{a}}$, Charlene Ranadheera ${ }^{\mathrm{a}}$, Maurizio Botta ${ }^{\mathrm{b}, \mathrm{c}, *}$ \\ a PiKe Pharma GmbH, Zurich, Switzerland \\ b Dipartimento Biotecnologie, Chimica e Farmacia, Università degli Studi di Siena, via A. Moro, 53100 Siena, Italy \\ 'Sbarro Institute for Cancer Research and Molecular Medicine, Center for Biotechnology, College of Science and Technology, Temple University, \\ BioLife Science Bldg., Suite 333, 1900 N 12th Street, Philadelphia, PA 19122, USA
}

\section{A R T I C L E I N F O}

Article history:

Received 28 June 2013

Revised 8 August 2013

Accepted 9 August 2013

Available online 17 August 2013

\section{Keywords:}

Antiviral agents

Influenza virus

Viral RNA polymerase

Benzofurazan

H1N1

\begin{abstract}
A B S T R A C T
The identification of a novel hit compound inhibitor of the protein-protein interaction between the influenza RNA-polymerase PA and PB1 subunits has been accomplished by means of high-throughput screening. A small family of structurally related molecules has been synthesized and biologically evaluated with most of the compounds showing micromolar potency of inhibition against viral replication.
\end{abstract}

(c) 2013 Elsevier Ltd. All rights reserved.
Human influenza viruses belong to the Orthomyxoviridae family, which consists of the genera influenza A, B, and C viruses. The Orthomyxoviridae are enveloped viruses containing a segmented, single-stranded, negative-sense RNA genome. While influenza $A($ FluA) viruses naturally infect a variety of animal as well as humans, influenza B (FluB) and C (FluC) viruses have been isolated predominantly from humans so far. ${ }^{1}$ The recent emergence of the novel H1N1 influenza virus of swine origin ${ }^{2-4}$ has directed the world's attention towards influenza A viruses due to their ability to cause global pandemics, such as the 1918 'Spanish' flu. Over the past century, mankind has relied mainly on vaccination in the fight against viral pathogens. As a consequence, very few antiviral drugs are available to date. However, in the absence of vaccines during the first wave of infections, antivirals are the only direct medical intervention for providing both protection against disease and therapeutic benefit to infected persons. Of the two classes of drugs approved for clinical use against influenza, the oldest and most affordable molecules are the M2 inhibitors, amantadine $\mathbf{1}$ and rimantadine $2 .{ }^{5}$ However, their use is actively discouraged due to huge viral resistance worldwide. The second class of anti-influenza drugs is represented by the neuraminidase (NA) inhibitors, namely the

\footnotetext{
* Corresponding author. Tel.: +39 0577 234306; fax: +39 0577234333.

E-mail addresses: botta.maurizio@gmail.com, botta@unisi.it (M. Botta).
}

oseltamivir (3, Tamiflu $\left.{ }^{\circledR}\right)$ and the zanamivir (4, Relenza ${ }^{\circledR}$ ) possessing an improved safety profile when compared to M2 inhibitors (Fig. 1).

Nevertheless, many influenza A strains, including the H1N1 strains circulating in Europe and in the US, are already resistant to oseltamivir, ${ }^{6,7}$ suggesting a limited range of use for this type of drug. Moreover, the drug resistance is not restricted to FluA only, since the emergence of FluB viruses with reduced sensitivity to neuraminidase inhibitors has been recently demonstrated. ${ }^{8,9}$ Hence, due to the continued emergence of new influenza variants, drug-resistant mutants and potential pandemic strains, our interest was directed toward the identification and development of new effective antiviral therapeutics. Over the last two decades, an increasing research effort has focused on the modulation of protein-protein interactions (PPIs) in order to develop novel therapeutic approaches and target-selective agents in drug discovery. The trimeric influenza RNA polymerase complex, consisting of the PB1, PB2 and PA subunits, is an attractive target for inhibition of viral replication due to the high level of conservation among different viruses and the low risk of resistance development. Since the N-terminal PA-interaction domain is highly conserved in different virus strains, molecules able to block the crucial PA-PB1 interaction can be expected to inhibit most, if not all, influenza viruses. Recently, Schwemmle et al. ${ }^{10}$ reported the feasibility of targeting the protein-protein 


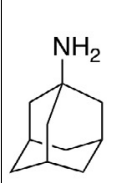

1

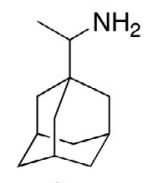

2<smiles>C=N[C@@H]1CC=C(C(=O)OCC)C[C@H]1OC(CC)CC</smiles>

3

$\mathrm{NH}_{2}$

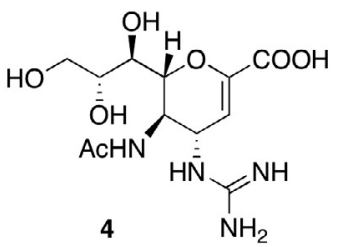

High-throughput screening approach

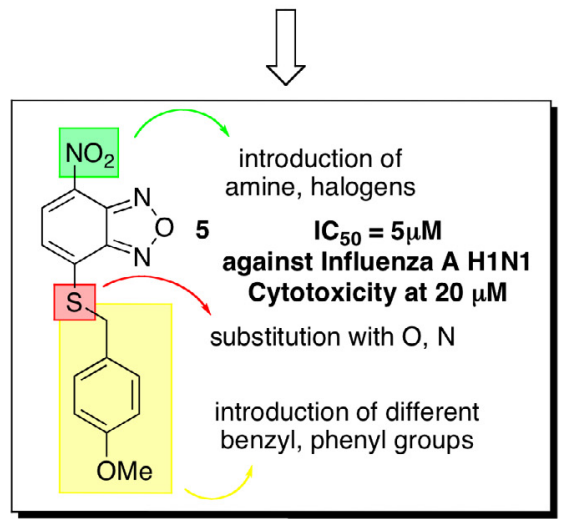

Figure 1. Commercially available antiviral compounds and the hit compound $\mathbf{5 .}$

interaction domain between the PB1 and PA subunits using a small peptide derived from the PA-binding domain of PB1.

In order to identify chemical compounds that efficiently block the PA-PB1 interaction, the novel biochemical ELISA-based screening approach described for influenza peptides ${ }^{10,11}$ was adapted to screen a set of chemical libraries and natural and antiviral compounds collections. A total of 15,000 molecules was subjected to binding assays to PA subunit. ${ }^{10,12}$ The inhibitory concentration $\left(\mathrm{IC}_{50}\right)$ was determined only for compounds that reported a positive outcome in the ELISA prescreen. A Plaque Reduction assay on MDCK cells infected with the virus A/WSN/33 (H1N1) was used for the determination of $\mathrm{IC}_{50} \cdot{ }^{13}$ This approach lead us to the identification of the hit benzofurazan compound 5 that showed inhibition of viral replication at micromolar level ( IC $_{50}=5 \mu \mathrm{M}$ ) (Fig. 1). Benzofurazans are a class of compounds known for their fluorescent properties thus possessing broad application in medicinal chemistry and biology. However, no examples of benzofurazans endowed with anti-influenza activity have been reported so far. Thus, in order to explore the chemical space around the benzofurazan core, evaluate the structure-activity relationships (SARs) and increase the activity of the hit compound $\mathbf{5}$, the synthesis of a series of analogues was planned. In particular, modifications at position C4, such as the displacement of nitro group with amines or chlorine, and at $\mathrm{C7}$, such as the introduction of different benzylic and (thio)phenolic substituents, were carried out (Fig. 1). Herein, we report our preliminary studies on the evaluation of the antiinfluenza A activity and cytotoxicity of a series of novel benzofurazan compounds.

The hit compound $\mathbf{5}$ and the corresponding analogues $\mathbf{7 a - v}$ were rapidly obtained in high yields through an aromatic nucleophilic substitution reaction on the commercially available 4-chloro-7-nitro benzofurazan $\mathbf{6}^{14}$ under fairly mild conditions. Refluxing of $\mathbf{6}$ with an equimolar amount of the appropriate nucleophile (benzylthiol, thiophenol, phenol) for $20 \mathrm{~min}$ in presence of catalytic amount of pyridine or KOAc afforded the desired compounds 7a-v (Scheme 1). Unsurprisingly, the reaction of nucleophiles 2-aminophenol, 4-aminophenol and 2-aminothiophenol with 6 led to the formation of the corresponding amino-derivatives $7 \mathbf{t}$, $7 \mathbf{u}$, and $7 \mathbf{v}$ in place of the desired $O$ or $S$ benzofurazan derivatives, presumably due to the higher nucleophilicity of the amine group under these reaction conditions. The synthesis of the $O$-benzyl benzofurazan 11 proved to be challenging (Table 1 ). Attempts to synthesize $\mathbf{1 1}$ by nuclophilic substitution on $\mathbf{6}$ under standard conditions were unsuccessful (entry 1 ). Neither the use of benzyl alcohol sodium salt as nucleophile led to desired $\mathbf{1 1}$ (entries 2 and 3). Finally, a Ullman type reaction was planned: benzofurazan 6 was reacted with benzyl alcohol in the presence of $20 \% \mathrm{CuI}$ and

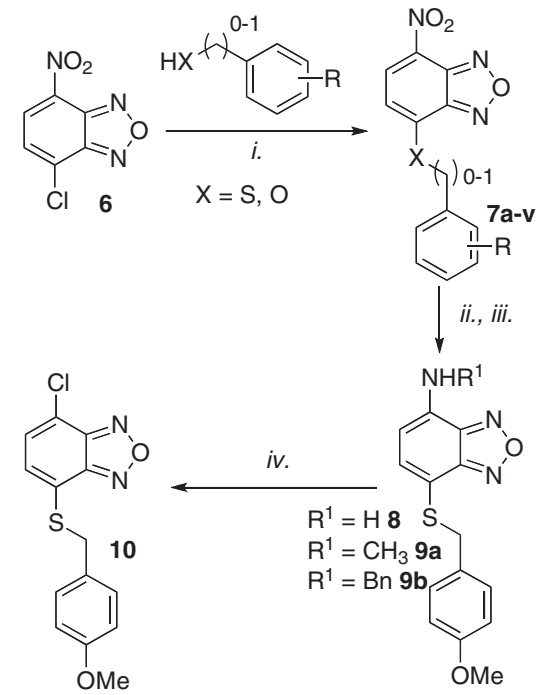

Scheme 1. Reagents and conditions: (i) catalytic amount of pyridine or KOAc, EtOH reflux, $20 \mathrm{~min}$; (ii) $\mathrm{Fe}, \mathrm{HCl}, \mathrm{DCM} / \mathrm{MeOH}$, rt, $25 \mathrm{~min}$; (iii) (a) $\mathrm{R}^{1}=\mathrm{CH}_{3}$ : paraformaldehyde, $\mathrm{Na}, \mathrm{NaBH}_{4}, \mathrm{MeOH}$, reflux, $1 \mathrm{~h}$; (b) $\mathrm{R}^{1}=\mathrm{Bn} /$ benzaldehyde, $\mathrm{NaBH}_{4} / \mathrm{PTSA}, \mathrm{DCE}$, rt, 16 h; (iv) $8, \mathrm{CuCl}_{2}$, tert-butyl nitrite, $\mathrm{CH}_{3} \mathrm{CN}, 65^{\circ} \mathrm{C}, 3 \mathrm{~h}$.

$\mathrm{Cs}_{2} \mathrm{CO}_{3}$ under microwave irradiation, affording desired derivative 11 in acceptable 24\% yield (entry 7). Comparable yields were obtained reacting 6 with $\mathrm{BnOH}$ in the presence of $2 \% \mathrm{Pd}(\mathrm{AcO})_{2}$ (entry 8). Finally, modifications at C4 were carried out treating thiobenzyl derivative $\mathbf{5}$ with $\mathrm{Fe}$ in $\mathrm{HCl}$ which led to the formation of the corresponding amine $\mathbf{8}$. Reductive amination of $\mathbf{8}$ with benzaldehyde or paraformaldehyde afforded alkyl derivatives $\mathbf{9 a - b}$, whilst treatment of $\mathbf{8}$ with $\mathrm{CuCl}_{2}$ in the presence of ${ }^{t} \mathrm{BuONO}$ led to the chloroderivative $\mathbf{1 0 .}$

The synthesized compounds were then assayed to evaluate their inhibitory activity toward influenza virus strain A/WSN/33 (H1N1). Results are reported in Table 2.

Compounds 7a-c (entries 2-4), bearing a fluoro/chloro-benzyl or benzyl chain, resulted inactive, while the bromo derivative compound 7d prove to be as active as the hit compound $\mathbf{5}$. However, 7d showed higher cytotoxicity than $\mathbf{5}$. On the other hand, the presence of a nitro group on the benzylic chain of compound 7e (entry 6) produced an increase of the anti-viral activity. Compound 7e proved to be active at $1-2.5 \mu \mathrm{M}$ and showed a cytotoxic profile similar to 5. In general the replacement of the thiobenzyl chain with substituted thiophenol moieties resulted in compounds (entries 9-14) displaying medium/good activity. Interestingly, all thiophenol derivatives $\mathbf{7 h}-\mathbf{m}$ showed a better cytotoxic profile 
Table 1

Synthesis of 0 -benzyl derivative $\mathbf{1 1}$

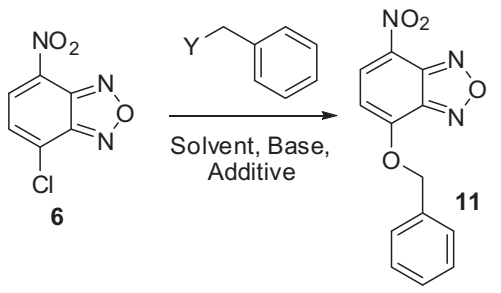

\begin{tabular}{lllrlll}
\hline Entry & $\mathrm{Y}$ & Solvent & $\mathrm{T}{ }^{\circ} \mathrm{C}$ & Base & Additive & Yield (\%) \\
\hline 1 & $\mathrm{OH}$ & EtOH & 78 & KOAc & - & $\mathrm{NR}^{\mathrm{a}}$ \\
2 & $\mathrm{ONa}$ & $\mathrm{THF}$ & 25 & - & - & $\mathrm{NR}^{\mathrm{a}}$ \\
3 & $\mathrm{ONa}$ & $\mathrm{THF}$ & 78 & - & - & $\mathrm{NR}^{\mathrm{a}}$ \\
4 & $\mathrm{OH}$ & Toluene & 80 & $\mathrm{Cs}_{2} \mathrm{CO}_{3}$ & $5 \%$ CuI, 10\% Phen & $\mathrm{ND}^{\mathrm{d}}$ \\
5 & $\mathrm{OH}$ & Toluene & $80^{\mathrm{c}}$ & $\mathrm{Cs}_{2} \mathrm{CO}_{3}$ & $5 \% \mathrm{CuI}, 10 \% \mathrm{Phen}^{\mathrm{d}}$ & 9 \\
6 & $\mathrm{OH}$ & Toluene & $120^{\mathrm{c}}$ & $\mathrm{Cs}_{2} \mathrm{CO}_{3}$ & $5 \% \mathrm{CuI}, 10 \%$ Phen & 12 \\
7 & $\mathrm{OH}$ & Toluene & $120^{\mathrm{c}}$ & $\mathrm{Cs}_{2} \mathrm{CO}_{3}$ & $10 \% \mathrm{CuI}, 10 \%$ Phen & 24 \\
8 & $\mathrm{OH}$ & Toluene & $80^{\mathrm{c}}$ & $\mathrm{Cs}_{2} \mathrm{CO}_{3}$ & $2 \% \mathrm{Pd}(\mathrm{OAc})_{2}$ BINAP & 20 \\
\hline
\end{tabular}

${ }^{a}$ NR No reaction, starting benzofurazan was recovered

b Not detected. Benzofurazan 6 decomposed

c Carried out under microwave irradiation, $10 \mathrm{~min}$

d Phenantroline.

Table 2

Activity and cytotoxicty of compounds 5, 7, 9, 10, 11 toward influenza virus strain A WSN/33
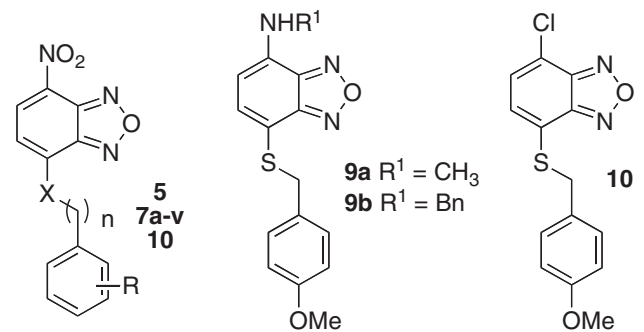

\begin{tabular}{|c|c|c|c|c|c|c|}
\hline Entry & Compound & $\mathrm{X}$ & $n$ & $\mathrm{R}$ & $\mathrm{IC}_{50}$ & Cytotox. \\
\hline 1 & 5 & $\mathrm{~S}$ & 1 & 4-OMe & $5 \mu \mathrm{M}$ & $20 \mu \mathrm{M}$ \\
\hline 2 & $7 a$ & $\mathrm{~S}$ & 1 & $\mathrm{H}$ & Inactive & $20 \mu \mathrm{M}$ \\
\hline 3 & $7 \mathbf{b}$ & $S$ & 1 & $4-\mathrm{Cl}$ & Inactive & - \\
\hline 4 & 7c & $\mathrm{S}$ & 1 & $4-\mathrm{F}$ & Inactive & $20 \mu \mathrm{M}$ \\
\hline 5 & 7d & $\mathrm{S}$ & 1 & $4-\mathrm{Br}$ & $\geqslant 5 \mu \mathrm{M}$ & $>10 \mu \mathrm{M}$ \\
\hline 6 & $7 e$ & $S$ & 1 & $3-\mathrm{NO}_{2}$ & $1-2.5 \mu \mathrm{M}$ & $20 \mu \mathrm{M}$ \\
\hline 7 & $7 f$ & $\mathrm{~S}$ & 0 & 4-OMe & Inactive & $40 \mu \mathrm{M}$ \\
\hline 8 & $7 g$ & $\mathrm{~S}$ & 0 & $\mathrm{H}$ & Inactive & $20 \mu \mathrm{M}$ \\
\hline 9 & $7 \mathbf{h}$ & $\mathrm{S}$ & 0 & $4-\mathrm{Cl}$ & $10-20 \mu \mathrm{M}$ & $40 \mu \mathrm{M}$ \\
\hline 10 & $7 i$ & $\mathrm{~S}$ & 0 & $4-F$ & $5-10 \mu \mathrm{M}$ & $40 \mu \mathrm{M}$ \\
\hline 11 & $7 \mathbf{j}$ & $S$ & 0 & $4-\mathrm{Br}$ & $10-20 \mu \mathrm{M}$ & $40 \mu \mathrm{M}$ \\
\hline 12 & $7 k$ & $S$ & 0 & $4-\mathrm{NO}_{2}$ & $10-20 \mu \mathrm{M}$ & $40 \mu \mathrm{M}$ \\
\hline 13 & 71 & $\mathrm{~S}$ & 0 & 3- $\mathrm{NH}_{2}$ & $10 \mu \mathrm{M}$ & $40 \mu \mathrm{M}$ \\
\hline 14 & $7 m$ & $\mathrm{~S}$ & 0 & $2-\mathrm{Br}$ & $>10 \mu \mathrm{M}$ & $40 \mu \mathrm{M}$ \\
\hline 15 & $7 n$ & 0 & 0 & 4-OMe & $30 \mu \mathrm{M}$ & $60 \mu \mathrm{M}$ \\
\hline 16 & 7o & $\mathrm{O}$ & 0 & $4-\mathrm{CN}$ & Inactive & - \\
\hline 17 & $7 p$ & $\mathrm{O}$ & 0 & $4-\mathrm{CH}_{2} \mathrm{CH}_{2} \mathrm{OH}$ & $10 \mu \mathrm{M}$ & $20 \mu \mathrm{M}$ \\
\hline 18 & $7 q$ & 0 & 0 & $4-\mathrm{CHO}$ & $20-40 \mu \mathrm{M}$ & $>40 \mu \mathrm{M}$ \\
\hline 19 & $7 r$ & $\mathrm{O}$ & 0 & $3-\mathrm{Br}$ & $20 \mu \mathrm{M}$ & $>40 \mu \mathrm{M}$ \\
\hline 20 & $7 \mathrm{~s}$ & 0 & 0 & 3-OMe & Inactive & - \\
\hline 21 & $7 t$ & $\mathrm{NH}$ & 0 & $2-\mathrm{OH}$ & Inactive & - \\
\hline 22 & $7 \mathbf{u}$ & $\mathrm{NH}$ & 0 & $2-\mathrm{SH}$ & $20-24 \mu \mathrm{M}$ & $>80 \mu \mathrm{M}$ \\
\hline 23 & $7 v$ & $\mathrm{NH}$ & 0 & $4-\mathrm{OH}$ & Inactive & - \\
\hline 25 & 9a & - & - & - & Inactive & - \\
\hline 26 & $9 b$ & - & - & - & Inactive & - \\
\hline 27 & 10 & - & - & - & Inactive & - \\
\hline 28 & 11 & $\mathrm{O}$ & 1 & $\mathrm{H}$ & Inactive & - \\
\hline
\end{tabular}

than $\mathbf{5}$. In particular, compound $\mathbf{7 i}$ (entry 10) showed a lower cytotoxicity and a biological profile similar to $\mathbf{5}$ and higher than its parent thiobenzyl derivative 7c. Conversely, the replacement of the sulphur atom with an oxygen or a nitrogen in compounds $\mathbf{7 n - v}$ and $\mathbf{1 1}$ resulted to be detrimental to activity even if those compounds were found to be less cytotoxic than 5. Only compound 7q showed an activity comparable with the other thio-analogues. However, 7q displayed higher cytotoxicity than its oxygenated or amino analogues but comparable with $\mathbf{5}$. Finally the substitution of the nitro group with an amino moiety or a chlorine atom led to inactive compounds (entries 25-27).

In conclusion, benzofurazan $\mathbf{5}$ was identified from high throughput screening and showed promising antiviral activity as anti-influenza A (H1N1) compound. A series of analogues bearing different substituents at $\mathrm{C} 4$ and $\mathrm{C} 7$ was thus synthesized in order to preliminary evaluate structure-activity relationships. One of the compounds, namely 7e, showed higher activity against H1N1 strains and a cytotoxicity profile similar to hit compound $\mathbf{5}$. A number of thioaryl derivatives $\mathbf{7 h}-\mathbf{0}$ showed antiviral activity comparable to $\mathbf{5}$ as well as improved cytotoxic profile. Further modifications have been planned in order to obtain new derivatives with increased activity toward influenza A virus H1N1 and a better cytotoxic profile. Moreover, biological studies to evaluate the ability of benzofurazan derivatives to disrupt the RNA polymerase PA-PB1 subunit interaction are currently in progress in our laboratories.

\section{Acknowledgments}

We gratefully acknowledge financial support provided by FP7 FLUINHIBIT (Ref. 201634) and FP7 FLUCURE (Ref. 259972) projects.

\section{Supplementary data}

Supplementary data associated with this article can be found, in the online version, at http://dx.doi.org/10.1016/j.bmcl.2013. 08.048.

\section{References and notes}

1. Chen, R.; Holmes, E. C. J. Mol. Evol. 2008, 66, 655.

2. Tumpey, T. M.; Belser, J. A. Annu. Rev. Microbiol. 2009, 63, 79.

3. Parrish, C. R.; Kawaoka, Y. Annu. Rev. Microbiol. 2005, 59, 553.

4. Neumann, G.: Noda, T.: Kawaoka, Y. Nature 2009, 459, 931.

5. Davies, W. L.; Grunert, R. R.; Haff, R. F.; McGahen, J. W.; Neumayer, E. M.; Paulshock, M.; Watts, J. C.; Wood, T. R.; Hermann, E. C.; Hoffmann, C. E. Science 1964, 144, 862.

6. Moscona, A. N. Engl. J. Med. 2009, 360, 953.

7. Dharan, N. J.; Gubareva, L. V.; Meyer, J. J.; Okomo-Adhiambo, M.; McClinton, R. C: Marshall, S. A.; St. George, K.; Epperson, S.; Brammer, L.; Klimov, A. L. Bresee, J. S.; Fry, A. M. JAMA 2009, 301, 1034.

8. Hatakeyama, S.; Sugaya, N.; Ito, M.; Yamazaki, M.; Ichikawa, M.; Kimura, K.; Kiso, M.; Shimi-zu, H.; Kawakami, C.; Koike, K.; Mitamura, K.; Kawaoka, Y. JAMA 2007, 297, 1435.

9. Gubareva, L. V.; Matrosovich, M. N.; Brenner, M. K.; Bethell, R. C.; Webster, R. G. J. Infect. Dis. 1998, 178, 1257.

10. Wunderlich, K.: Mayer, D.: Ranadheera, C.: Holler, A. S.; Mänz, B.: Martin, A. Chase, G.; Tegge, W.; Frank, R.; Kessler, U.; Schwemmle, M. PLoS One 2009, 10, 7517. The peptide de-scribed in the paper of Schwemmle and co-workers $\left(\mathrm{IC}_{50}=1.8 \mathrm{nM}\right)$ was used as the positive control of the ELISA screening assay..

11. Ghanem, A.; Mayer, D.: Chase, G.; Tegge, W.; Frank, R.; Kochs, G.; Garcia-Sastre, A.; Schwemmle, M. J. Virol. 2007, 81, 7801.

12. (a) Berg, T. Angew. Chem., Int. Ed. 2003, 42, 2462; Coen, D. M.; Pilger, B. D. 2003, WO 2002095054 A3.

13. Schmidtke, M.; Schnittler, U.; Jahn, B.; Dahse, H.; Stelzner, A. J. Virol. Methods 2001, 95, 133.

14. Ghosh, P. B.; Whitehouse, M. W. J. Med. Chem. 1968, 11, 305. 